Research Article

\title{
Effects of Constant Amplitude Cyclic Loading on the Nonuniform Deformation of Sandstone Specimens
}

\author{
Xiao-Bin Yang $\mathbb{D}^{1,},{ }^{1,2}$ Xin-Xing Han $\mathbb{D}^{1},{ }^{1}$ Xiao-Yao Wang $\mathbb{D}^{1},{ }^{1}$ and Zi-Peng Zhang $\mathbb{D}^{1}$ \\ ${ }^{1}$ School of Resource and Safety Engineering, China University of Mining and Technology (Beijing), Beijing, China \\ ${ }^{2}$ Beijing Key Laboratory for Precise Mining of Intergrown Energy and Resources, Beijing, China \\ Correspondence should be addressed to Xiao-Bin Yang; yangxiaobin02@126.com
}

Received 24 February 2019; Revised 2 April 2019; Accepted 10 April 2019; Published 30 April 2019

Academic Editor: Zaobao Liu

Copyright $($ C 2019 Xiao-Bin Yang et al. This is an open access article distributed under the Creative Commons Attribution License, which permits unrestricted use, distribution, and reproduction in any medium, provided the original work is properly cited.

In order to explore the mechanical response mechanism of rock materials under cyclic loading, uniaxial constant amplitude cyclic loading tests for sandstone specimens were carried out. The images of specimen deformation during the tests were captured by charge-coupled device (CCD) cameras. Based on the digital image correlation method (DICM), the evolution laws of nonuniform deformation and displacements around localization bands during cyclic loading were investigated. The experimental results show that, during the cyclic loading process, the nonuniform deformation continually escalates with the number of cycles increasing and fluctuates with the cyclic loading stress condition; the nonuniform deformation lags behind the variation of loading stress; and the whole nonuniform deformation experiences a slow evolution stage and a fast evolution stage. At the loading stage or unloading stage, the nonuniform deformation of rock deteriorates with the number of cycles increasing under the same stress condition. In each loading cycle, the nonuniform deformation at the unloading stage is more than that at the loading stage under the same stress condition. The time of dislocation displacements and tension displacements meets hysteresis, compared with the time of stress change. In addition, the dislocation displacements and tension displacements around localization bands in general increase with the number of cycles increasing. The displacement evolution around localization bands has the same hysteresis and accumulation laws as that of nonuniform deformation.

\section{Introduction}

Rock is a complex and common heterogeneous geological material. The deformation and mechanical properties in its failure process are the foundation of rock mechanics. At the stage of geotechnical engineering construction and engineering operation, the rock mass is often subjected to cyclic loading. Therefore, finding out the deformation evolution laws of rock materials under cyclic loading is helpful to understand the failure mechanism of rock under cyclic loading, and further to evaluate the long-term stability of engineering rock mass, which benefits the design, construction, and protection of geotechnical engineering, both in theory and in practice.

Researchers have devoted great efforts to studying the deformation failure and mechanical properties of rocks under cyclic loading. Costin and Holcomb [1] presented a simple model which described the failure of brittle rock under cyclic compressive loading. Singh [2] carried out cyclic loading tests to investigate the fatigue and strain hardening behaviors of greywacke. Ray et al. [3] carried out cyclic loading tests of sandstone and explored the change laws of uniaxial compressive strength with the increase in the applied stress and loading cycles. Xu et al. [4] investigated the evolution laws of the closed plastic hysteresis loop of rock materials formed under cyclic loading and unloading conditions from the different displacement rates, the different load levels, and the different rock porosity. He et al. [5] carried out the cyclic loading tests of sandstone under different stress amplitude conditions and studied the deformation characteristics, the cyclic softening and cyclic hardening characteristics, and energy dissipation characteristics during the cyclic loading process. In addition, the evolution equation of dissipative energy with the number of 
cycles was also established. Vaneghi et al. [6] conducted uniaxial cyclic compression tests on granodiorite and sandstone specimens to explore the effects of cyclic loading conditions, loading amplitudes, and stress levels on the fatigue life of hard and soft rocks. Bagde and Petroš [7] studied the fatigue and dynamic energy behavior of rocks under cyclic loading. Jafari et al. [8] and White [9] studied the mechanical behavior and anisotropic damage of rock joints under cyclic loading. Chen et al. [10], Xia et al. [11], Li et al. [12], and Fu et al. [13] studied the acoustic emission characteristics of rocks under cyclic loading and unloading and investigated the deformation evolution of rocks from the perspective of acoustic emission. Song et al. [14] explored the change laws of resistivity in the process of rock failure under constant amplitude cyclic loading and found that the change of resistivity can well characterize the development of microfractures in specimens during the cyclic loading and unloading process. Song et al. $[15,16]$ used digital image correlation (DIC) to obtain the deformation fields and studied the damage evolution process and crack development of rocks under cyclic uniaxial compression. Zhou et al. $[17,18]$ carried out uniaxial cyclic loading tests for sandstone and studied the uniaxial cyclic loading strength, deformation characteristics, elastic mechanical properties, and the mechanical characteristics of rock during the fracture and damage process. Extensive achievements have been made in the above research work, but some issues still remain unsolved. It is generally believed that the nonuniform deformation evolution of rock, or the localization deformation of rock, leads to the ultimate failure of rock [19-23]. Previous researches rarely focus on the relationship between the deformation localization (nonuniform deformation degree) evolution of rock and the number of cycles, and the loading and unloading stress statement during the cyclic process; most of all, less work relates to the displacement evolution around localization bands of rock materials under cyclic loading conditions.

Conducting uniaxial constant amplitude cyclic loading tests on the sandstone samples aims to reveal the relation between the nonuniform deformation laws and the number of cycles and stress condition, as well as the displacement evolution laws around localization bands with cyclic loading effect based on the digital image correlation method (DICM).

\section{Principle of DICM}

DICM also named digital speckle correlation method (DSCM) [24], which was proposed independently by Yamaguchi [25] and Peters and Ranson [26], has been improved by some researchers in recent years. The basic principle of DICM is that the speckle patterns centered at the measured point are matched in the speckle images before and after deformation, and the difference of coordinates of these two patterns is considered as the displacement of the measurement point. By repeating this procedure, a displacement field will be obtained and the strain field can also be calculated [27-31]. The schematic diagram of correlation match was shown in Figure 1 [32].

In Figure $1, I_{\mathrm{s}}$ and $I_{\mathrm{t}}$ are the two speckle images before and after deformation, respectively, in which $I_{\mathrm{s}}$ is the source

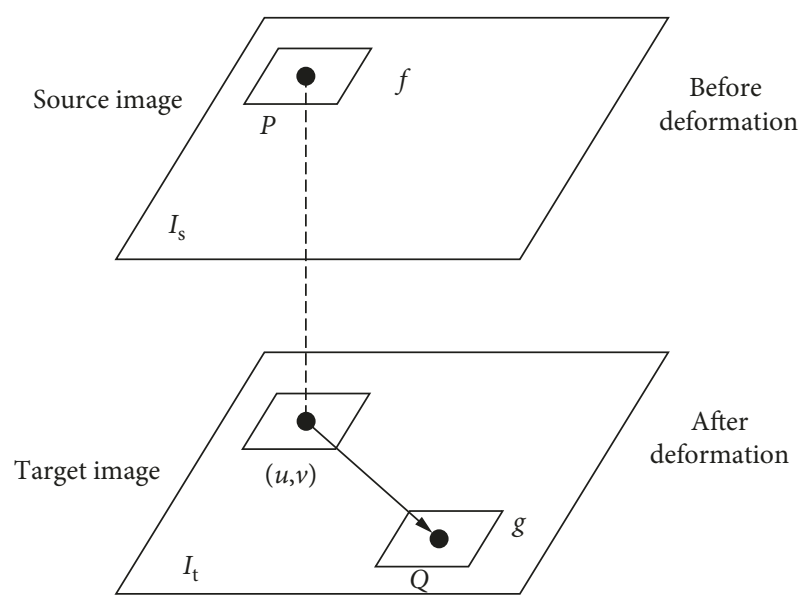

FIGURE 1: Schematic diagram of correlation match.

image, representing the starting state, and $I_{\mathrm{t}}$ is the target image, representing the state after deformation. If the motion of point $P$ on the $I_{\mathrm{s}}$ needs to be tracked, the matching point of point $P$ on the $I_{\mathrm{t}}$ needs to be solved. Therefore, the characteristic speckle pattern $f$ of point $P$ on the source image was selected first, and the most matched speckle pattern $g$ on the target image is searched by the method of correlation match. After the search is successful, the point $Q$ corresponding to the speckle pattern $g$ is the position of $P$ after deformation, and the coordinate differences $(u, v)$ of $P$ and $Q$ indicate the displacement. A correlation function is defined to represent the matching degree of speckle patterns $f$ and $g$ corresponding to the points $P$ and $Q$, respectively. For the correlation function (such as equation (1)) designed according to certain rules, the extreme point represents the best match [32, 33]. After completing pixel-level matching, special mathematical methods are used to get the location of matching points of the subpixel level, so as to achieve higher measurement accuracy:

$$
C=\frac{\sum_{i=1}^{m} \sum_{j=1}^{m}\left[p\left(x_{i}, y_{j}\right)-\bar{p}\right]\left[q\left(x_{i}^{*}, y_{j}^{*}\right)-\bar{q}\right]}{\sqrt{\sum_{i=1}^{m} \sum_{j=1}^{m}\left[p\left(x_{i}, y_{j}\right)-\bar{p}\right]^{2} \sum_{i=1}^{m} \sum_{j=1}^{m}\left[q\left(x_{i}^{*}, y_{j}^{*}\right)-\bar{q}\right]^{2}}},
$$

where $C$ is the correlation function; $p(x, y)$ is the gray-level value at coordinate $(x, y)$ for the speckle pattern before deformation; $\bar{p}$ is the average value of $p ; q\left(x^{*}, y^{*}\right)$ is the gray-level value at coordinate $\left(x^{*}, y^{*}\right)$ for the speckle pattern after deformation; $\bar{q}$ is the average value of $q$.

DICM is simple to operate and has the advantages of wide range of applicable test objects, no special requirements for measurement environment, high sensitivity, full field, and noncontacting [34-37]; it can accurately measure and calculate the nonuniform deformation of specimens in the uniaxial constant amplitude cyclic loading process even in the noise environment.

\section{Test System and Conditions}

The tested rock specimens are sandstones. Specimens are hexahedrons with a size of $50 \mathrm{~mm} * 50 \mathrm{~mm} * 100 \mathrm{~mm}$ and 
cut from the same sandstone block, according to the standards of International Society for Rock Mechanics (ISRM). The two end faces were polished to ensure the flat surfaces. Then, artificial speckle field was made by spraying paint on the surfaces of the specimens except the two end faces.

The electric-hydraulic servocontrol test machine was used for uniaxial constant amplitude cyclic loading tests, and CCD cameras were chosen to capture the speckle deformation images of the samples. Meanwhile, computers were used to analyze the deformation and control the test condition. The schematic diagram of the test system is shown in Figure 2, and the physical diagram is shown in Figure 3. In the process of testing, the speckle deformation images of specimen's surfaces were captured by CCD cameras at the image acquisition rate of 2 frames per second. The resolution of speckle deformation images was set as 1600 pixel $\times 1200$ pixel, and the resolution of the object surface was $0.1 \mathrm{~mm} /$ pixel.

At the beginning of the test, the test machine and the CCD cameras started at the same time. The test machine automatically recorded data such as load, time, and displacements. The CCD cameras continuously collected the speckle deformation images on the surface of specimens in the whole cyclic loading process.

Before the cyclic loading tests, the uniaxial compressive strength tests were done on three samples cut from the same sandstone block, taking the equipment storage and calculation complexity into account, the cyclic tests were carried out by load control, and the loading rate was $0.2 \mathrm{kN} / \mathrm{s}$. The load amplitudes were kept constant in each cycle, and the load amplitudes ranged from 0.3 to 0.8 of the uniaxial compressive strength. According to the measured uniaxial compressive strength, the cyclic load amplitude varied from $28 \mathrm{kN}$ to $70 \mathrm{kN}$ or the cyclic loading stress changed from 11.2 $\mathrm{MPa}$ to $28 \mathrm{MPa}$. The loading frequency is about $2.3467 \times 10^{-3} \mathrm{~Hz}$. The relation curve between load and time in the whole cyclic process, recorded automatically by the computer, is shown in Figure 4.

From Figure 4, there are seventeen complete cyclic loading cycles, at the eighteenth cycle, the failure occurred, and the failure load was $68.2 \mathrm{kN}$. The final failure pattern is shown in Figure 5, and the specimen ruptured through one main crack. It can be seen from Figure 5 that the main crack is composed of two straight cracks (crack 1 and crack 2), and the exfoliation phenomenon appeared on the right side of the rock specimen.

Digital image correlation method was used to analyze the evolution laws of nonuniform deformation and displacements around localization bands at the cracks by calculating all the deformation images in the whole cyclic loading process, the samples were proved eventually being destroyed in the tension mode and the exfoliation occurred at the moment of rock failure, and the flow chart of the whole research process is shown in Figure 6.

\section{Test Results and Discussion}

4.1. Evolution Analysis of Deformation. In the process of cyclic loading, the rock will undergo nonuniform

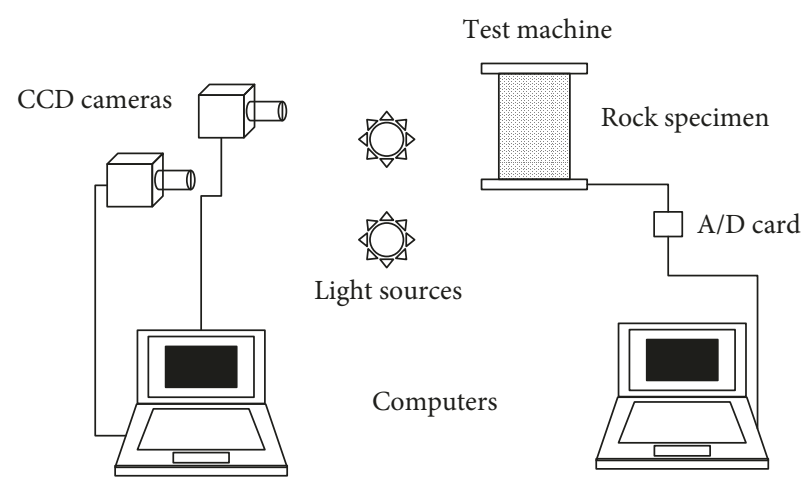

Specimen size: $50 \mathrm{~mm} * 50 \mathrm{~mm} * 100 \mathrm{~mm}$

Loading mode: uniaxial constant amplitude cyclic loading

FIgURE 2: Schematic diagram of test system.

deformation, i.e., the deformation localization of rock. Compared with the uniform deformation field before rock failure, the main differences of the localized deformation field are as follows [38, 39]: first, a few points or areas of the deformation (which are located inside the localization bands) in the deformation field are much larger than other points or areas (which are located outside the localization bands). These points/areas can be called the "numerical characteristics" of deformation localization. Second, a few points/areas of larger deformation are concentrated in a (or a few) connected bands, which can be called the "spatial characteristics" of deformation localization. Considering the two characteristics of localized deformation field different from uniform deformation field, here a statistical index $S_{w}$, which can simultaneously describe the "numerical characteristics" and "spatial characteristics" of deformation localization, is introduced to analyze the evolution of nonuniform deformation field of rock. The formula about the statistical index is expressed as follows [40]:

$$
S_{\mathrm{w}}=w_{\mathrm{s}} S
$$

where $S$ is the variance of the deformation field at a certain time and $w_{\mathrm{s}}$ is a weighting factor considering the "spatial characteristics" of deformation localization. The two variables are calculated as follows [40]:

$$
\begin{aligned}
S & =S\left(X_{k}\right)=\sqrt{\frac{1}{n-1} \sum_{k=1}^{n}\left(X_{k}-\bar{X}\right)^{2},} \\
w_{s} & =S\left(X_{k}^{*}\right)=\sqrt{\frac{1}{n-1} \sum_{k=1}^{n}\left(X_{k}^{*}-\overline{X^{*}}\right)^{2},} \\
\bar{X} & =\frac{1}{n} \sum_{k=1}^{n} X_{k}, \\
X^{*} & =X \otimes B,
\end{aligned}
$$

where $X_{k}$ is the deformation amount of each point in the deformation field; $\bar{X}$ is the average value of $X_{k} ; X^{*}$ is "spatially 


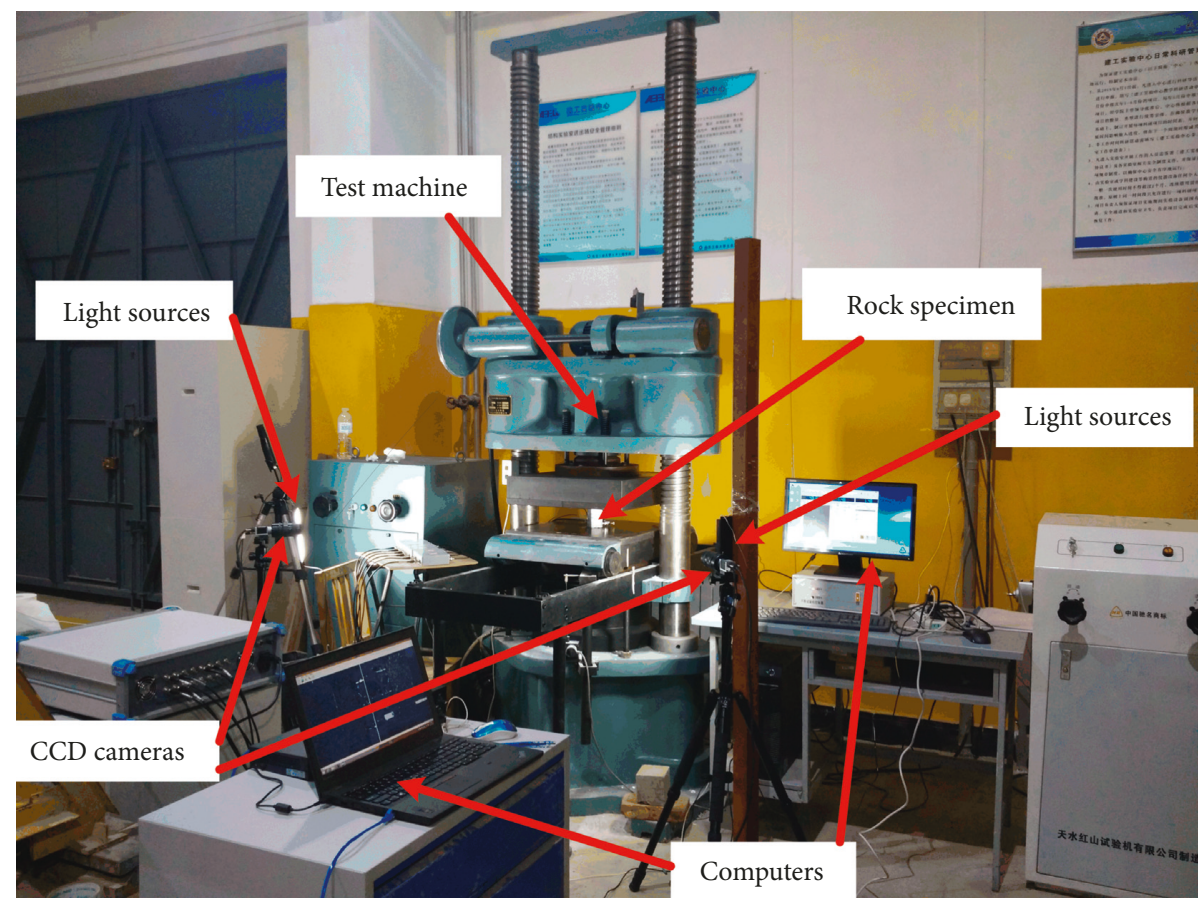

Figure 3: Physical diagram of test system.

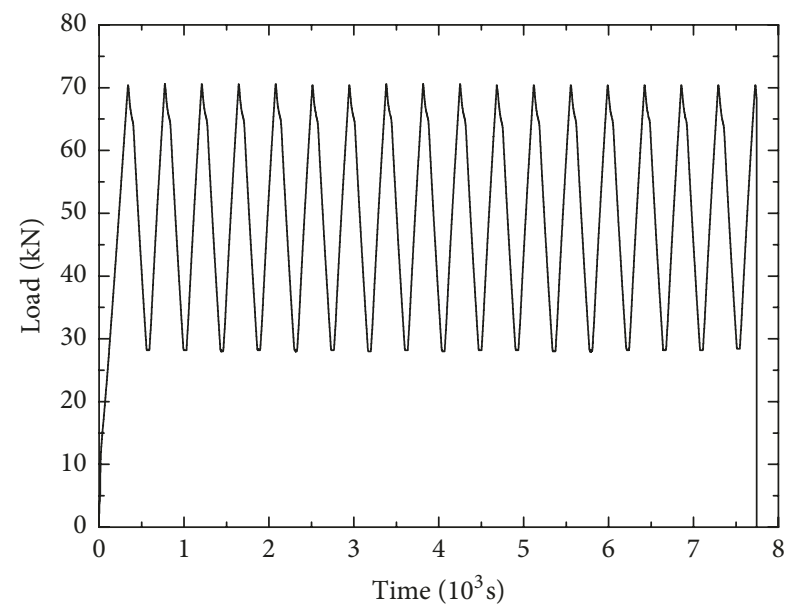

Figure 4: Curve of load and time.

treated" deformation field and is a convolution of matrix $X$ (data matrix of deformation field) and matrix $B$ (convolution kernel) whose elements are all 1, and the size is $m * m$.

From the above formulas, under normal circumstances, the variance $S$ of the localized deformation region (nonuniform deformation field) will be greater than the variance $S$ of the deformation field without localized deformation. When the localization bands appear, the evolution curve of the variance $S$ of deformation field with time (or nominal strain) will mutate, which reflects the abrupt feature of the occurrence of deformation localization (relative to the uniform deformation stage). Therefore, the variance $S$ of deformation field can describe the "numerical characteristics" of deformation localization. And $w_{\mathrm{s}}$ describing the "spatial characteristics" of deformation localization is the variance of the deformation field after convolution. According to the properties of convolution, the more the spatial concentration degree of deformation field is, the greater the $w_{\mathrm{s}}$ is. Therefore, the statistical index $S_{\mathrm{w}}$ obtained by multiplying $S$ and $w_{\mathrm{s}}$ can take account of the two characteristics of deformation localization (namely, nonuniform deformation), which can describe the nonuniform characteristics of deformation field.

Through calculating the deformation field of the specimen in the constant amplitude cyclic loading process, and normalizing the statistical index $S_{\mathrm{w}}$, the contrast curve of the statistical index $S_{\mathrm{w}}$ and stress was obtained, as shown in Figure 7.

From Figure 7 , in the process of constant amplitude cyclic loading of rock, the statistical index $S_{\mathrm{w}}$ of nonuniform deformation fluctuates with the loading and unloading stress. It basically shows that the value of $S_{w}$ increases gradually during the loading stage of each cycle and decreases gradually at the unloading stage of each cycle. But careful comparison of the $S_{\mathrm{w}}$ curve with the stress curve indicates that, in each cyclic loading and unloading process of rock sample, the value of $S_{\mathrm{w}}$ does not vary with the loading stress synchronously, and the nonuniform deformation always lags behind the variation of loading stress. The occurrence of this hysteresis is caused by the accumulative or fatigue damage in the process of cyclic loading of rock sample [41]. Rocks are heterogeneous, discontinuous, and anisotropic materials with microstructures such as holes, cracks, and inclusions inside. In the process of loading and unloading, the contact adhesion and stick-slip friction among mineral particles and microstructures in rock cause the nonuniform deformation to lag behind the loading stress. 


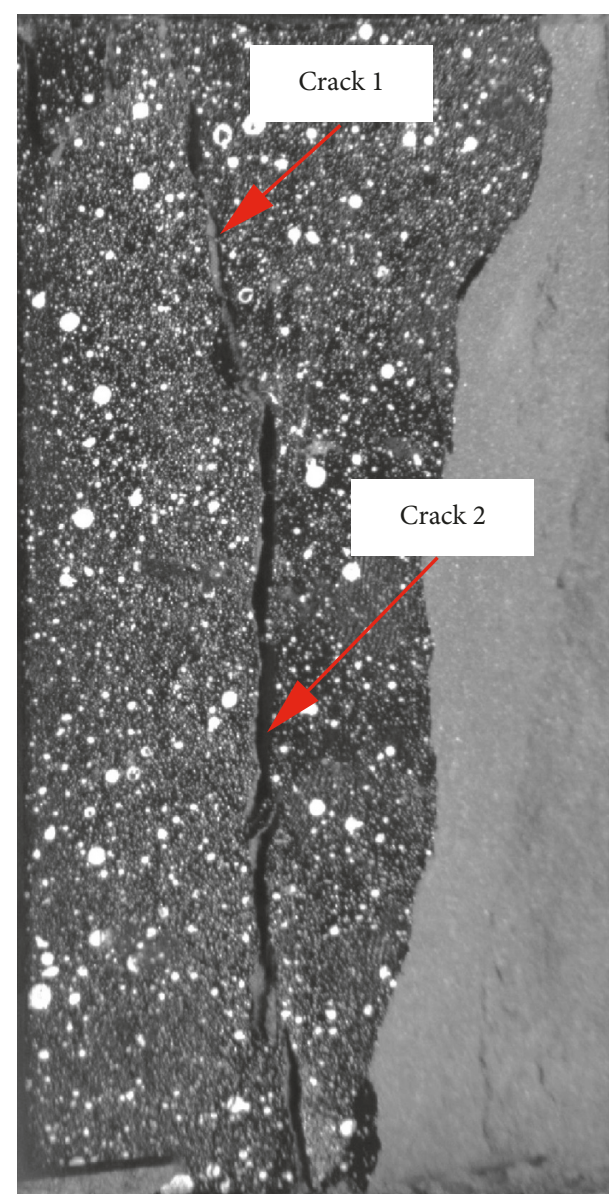

FIGURE 5: Failure pattern of specimen.

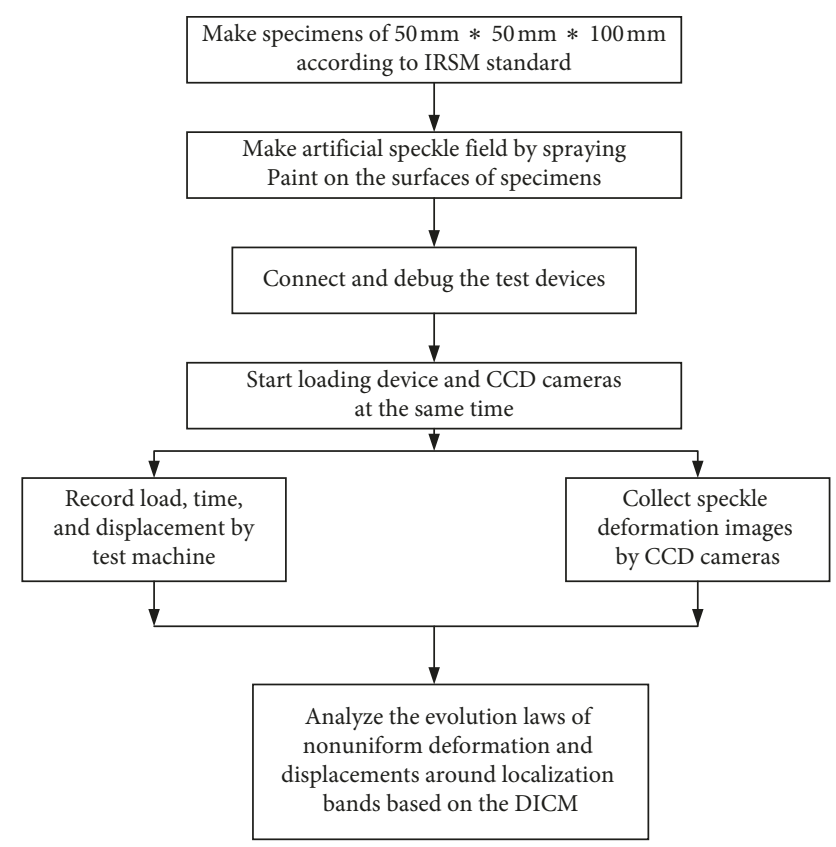

FIgURE 6: Flow chart of whole research process.

To explore the change laws of the nonuniform deformation of rock with the number of cycles in the constant amplitude cyclic loading process (the cyclic load amplitude

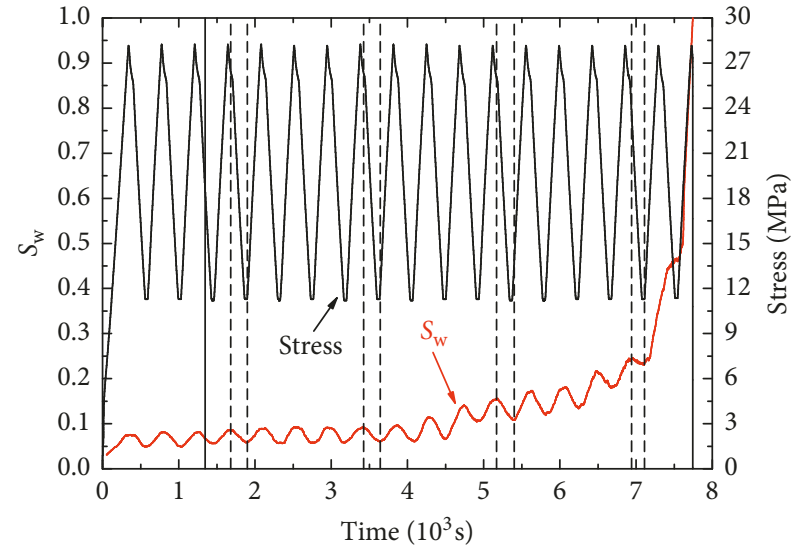

Figure 7: Contrast curve of $S_{\mathrm{w}}$ and stress.

varied from $28 \mathrm{kN}$ to $70 \mathrm{kN}$ or the cyclic loading stress changed from 11.2 MPa to $28 \mathrm{MPa}$ ), the value of $S_{\mathrm{w}}$ when loading and unloading to $15 \mathrm{MPa}, 20 \mathrm{MPa}, 25 \mathrm{MPa}$, the peak point of loading stress (PPL), and the bottom point of unloading stress (BPU) during each cycle was selected, and the evolution curves of $S_{\mathrm{w}}$ which varied with the number of cycles were drawn under the same stress level, as shown in Figure 8 .

Figure 8(a) gives the $S_{\mathrm{w}}$ curves that vary with the number of cycles at $15 \mathrm{MPa}$. With the number of cycles increasing, the value of $S_{\mathrm{w}}$ increases too. It shows that, before the $10^{\mathrm{th}}$ cycle, the value of $S_{\mathrm{w}}$ increases slowly with the number of cycles increasing. After the $10^{\text {th }}$ loading cycle, the value increases rapidly compared with the earlier loading cycles, and the slope of $S_{\mathrm{w}}$ curves increases with the number of cycles increasing. This indicates that the evolution rate of nonuniform deformation increases or the accumulative damage evolution rate increases. The analysis shows that there are two obvious stages in the process of nonuniform deformation evolution, i.e., the slow nonuniform deformation evolution stage and the fast nonuniform deformation evolution stage; following the fast nonuniform deformation evolution, the failure of rock sample occurs. By analyzing the $S_{\mathrm{w}}$ curves when loading and unloading to $15 \mathrm{MPa}$, it can be found that the value of $S_{\mathrm{w}}$ at the unloading stage is bigger than that at the loading stage under the same stress level, i.e., due to the accumulative effect of cyclic loading, when loading and unloading to the same stress in the same cycle, the nonuniform deformation at the unloading stage is bigger than that at the loading stage. This validates that cyclic loading can cause damage accumulation in rock materials. Likewise, Figures $8(\mathrm{~b})$ and $8(\mathrm{c})$ have the same laws as Figure 8(a).

As to Figure 8(d), because the stress value at the peak point of loading is bigger than that at the bottom point of unloading, the value of $S_{\mathrm{w}}$ at the peak point of loading stress is bigger than that at the bottom point of unloading stress before the $15^{\text {th }}$ loading cycle. After the $15^{\text {th }}$ loading cycle, the value of $S_{\mathrm{w}}$ at the bottom point of unloading stress turns bigger than that at the peak point of loading stress. And when entering the $17^{\text {th }}$ loading cycle, the value of $S_{\mathrm{w}}$ at the peak point of loading stress and the bottom point of 


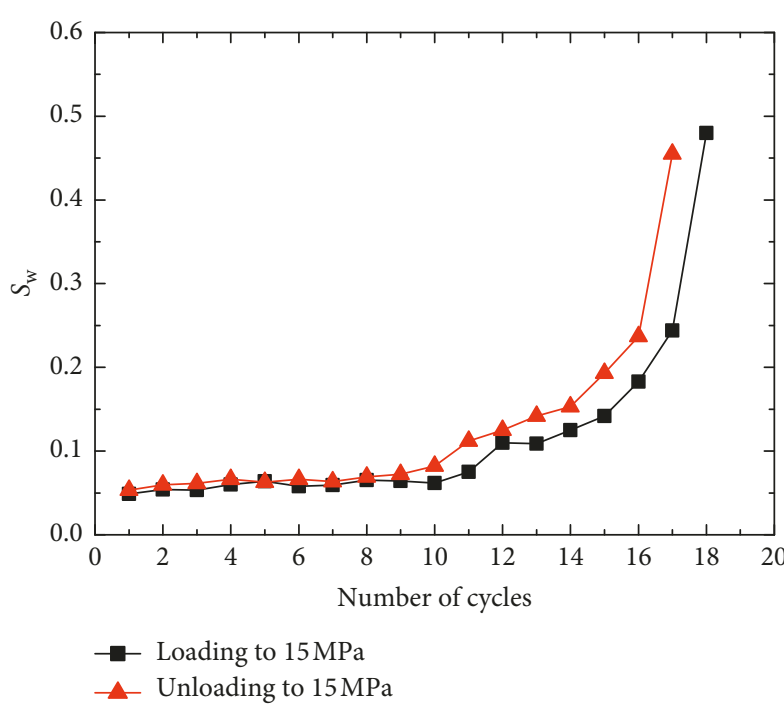

(a)

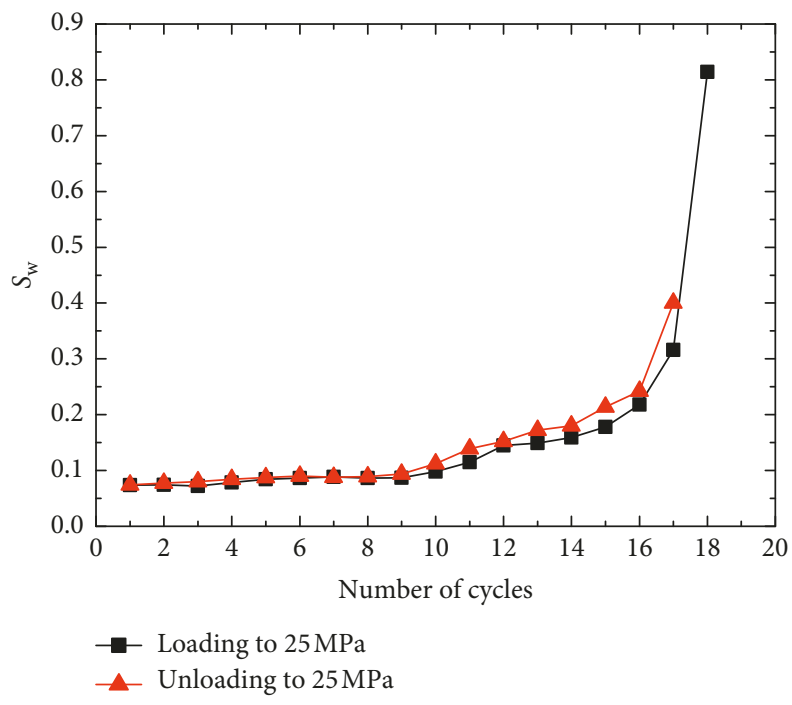

(c)

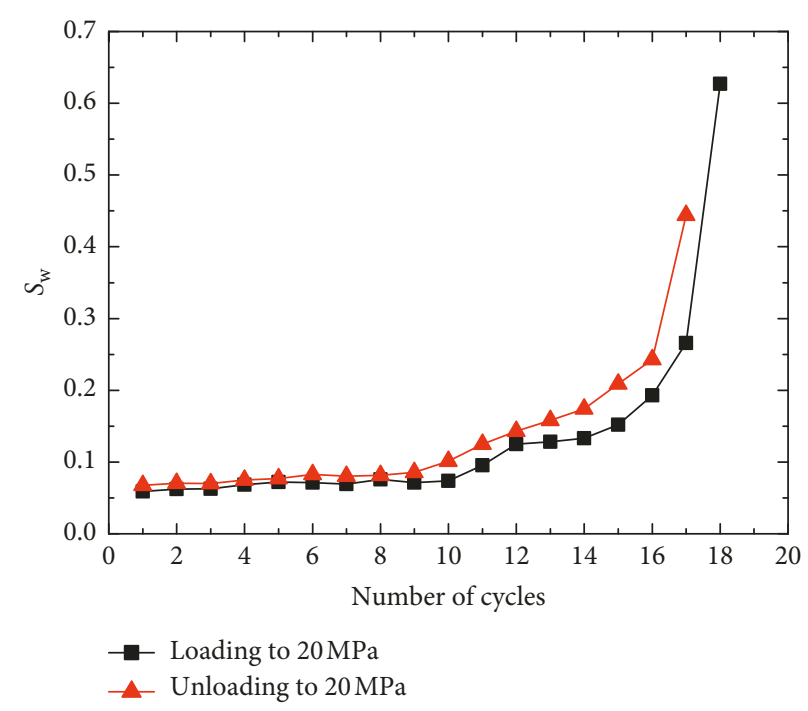

(b)

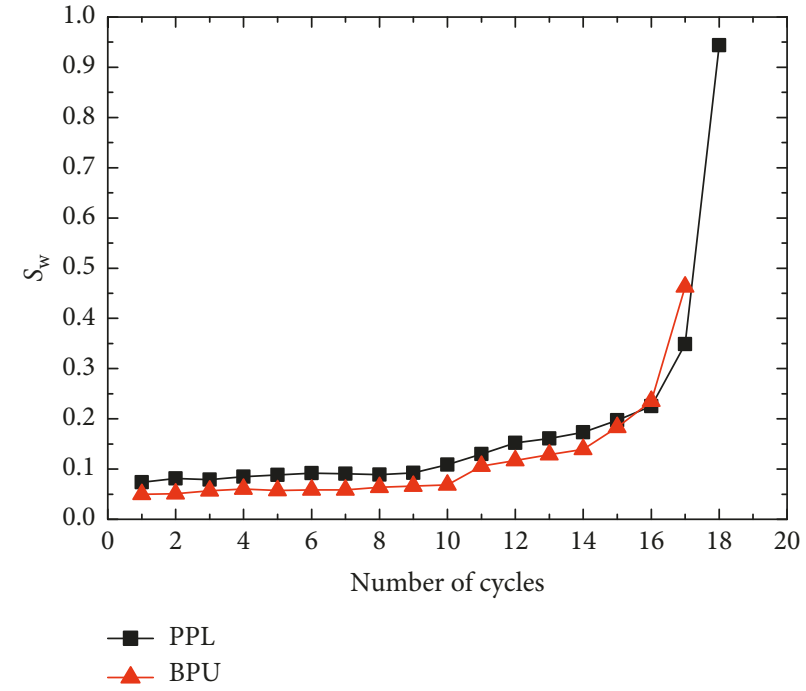

(d)

Figure 8: Evolution curves of $S_{\mathrm{w}}$ under the same stress: (a) loading or unloading to $15 \mathrm{MPa}$; (b) loading or unloading to $20 \mathrm{MPa}$; (c) loading or unloading to $25 \mathrm{MPa}$; (d) PPL or BPU.

unloading stress both significantly increase. The speckle images at the peak point of loading stress and the bottom point of unloading stress during the $15^{\text {th }}, 16^{\text {th }}$, and $17^{\text {th }}$ cycle were, respectively, selected to analyze this phenomenon.

The speckle image at the initial time was used as the reference image, and based on the DICM [42], the nephogram of maximum shear strain field at each corresponding time is shown in Figure 9, in which all nephograms are suitable for the same scale bar, and the characteristic parameters can be calculated by using the digital image correlation method. The length, width, and deformation value of localization band at each corresponding time are listed in Table 1.

As shown in Table 1 , from the $15^{\text {th }}$ cycle to the $17^{\text {th }}$ cycle, the length, width, and deformation value of localization band at the peak point of loading stress and the bottom point of unloading stress all keep increasing. The value decreases from the peak point of loading stress to the bottom point of unloading stress at the $15^{\text {th }}$ cycle, and there is still a deformation recovery. However, since the $16^{\text {th }}$ cycle, the value begins to increase from the peak point of loading stress to the bottom point of unloading stress, and at the $17^{\text {th }}$ cycle, the length and deformation value increase greatly.

The above analysis of the nephogram of deformation field indicates that, in the process of constant amplitude cyclic loading, the statistical index $S_{\mathrm{w}}$ can well reflect the nonuniform deformation of the specimen. In addition, with the increase of the number of cycles, the nonuniform deformation increases gradually, and the fatigue damage accumulates gradually. When the number of cycles increases to a certain one, the final nonuniform deformation of rock still increases, no matter at the loading stage or at the unloading stage, and the parameters of localization band still expand. When the damage accumulates to a 


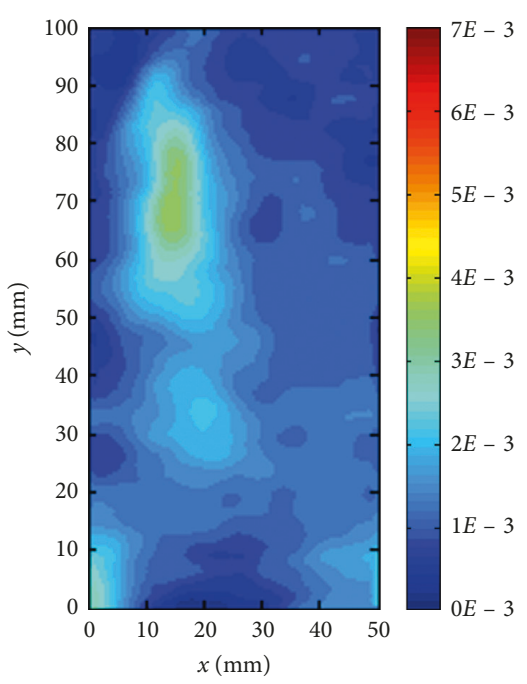

(a)

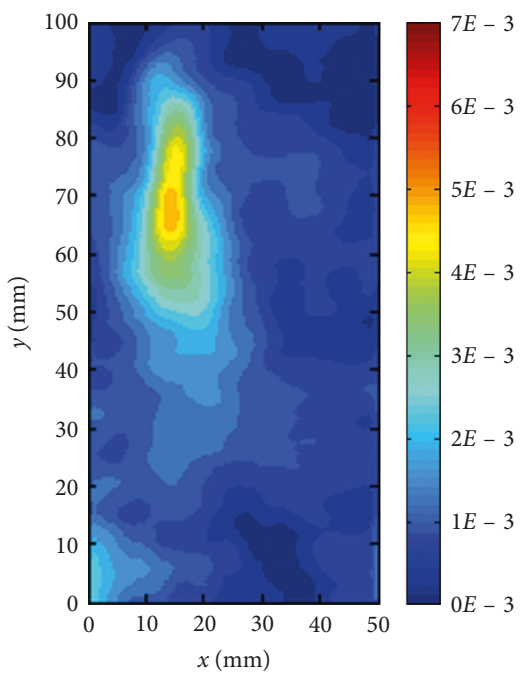

(d)

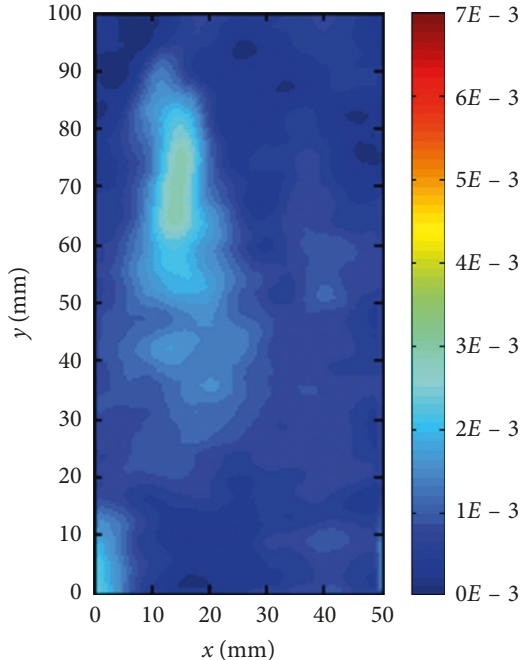

(b)

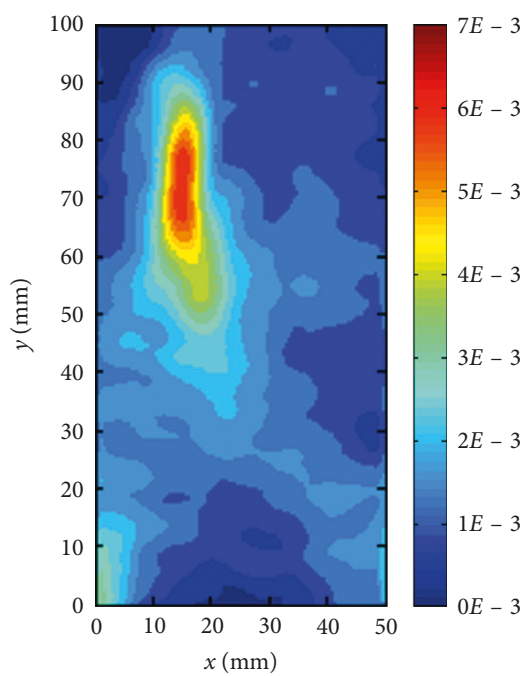

(e)

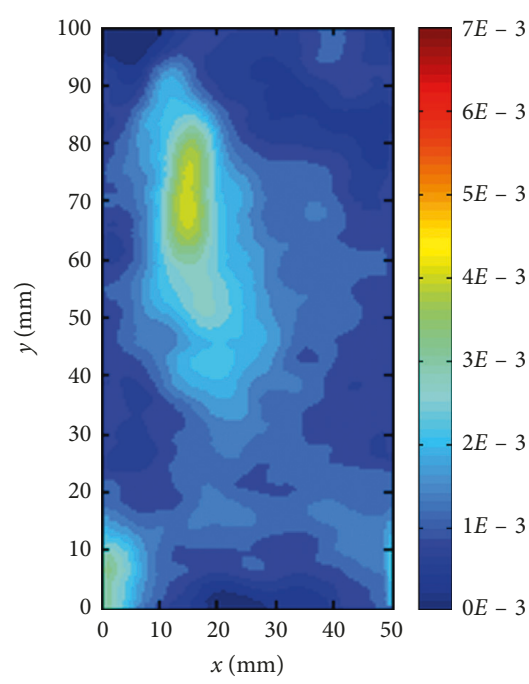

(c)

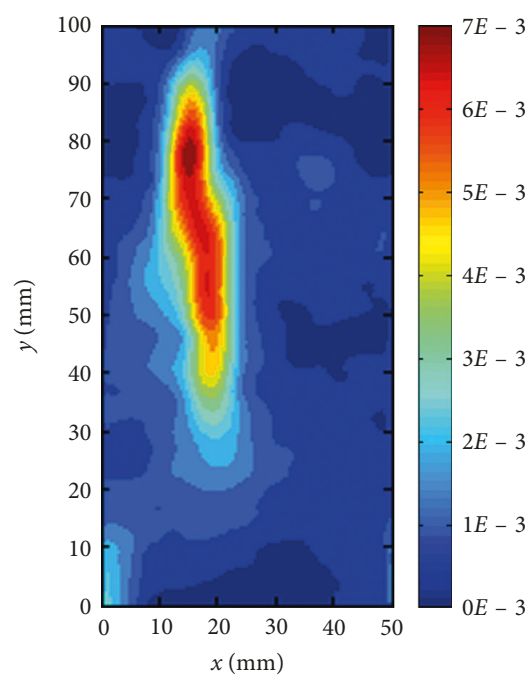

(f)

Figure 9: Nephogram of deformation field: (a) PPL at the $15^{\text {th }}$ cycle; (b) BPU at the $15^{\text {th }}$ cycle; (c) PPL at the $16^{\text {th }}$ cycle; (d) BPU at the $16^{\text {th }}$ cycle; (e) PPL at the $17^{\text {th }}$ cycle; (f) BPU at the $17^{\text {th }}$ cycle.

TABLE 1: Characteristic parameters of localization band at each corresponding time.

\begin{tabular}{lccc}
\hline $\begin{array}{l}\text { Corresponding } \\
\text { time }\end{array}$ & $\begin{array}{c}\text { Length } \\
(\mathrm{mm})\end{array}$ & $\begin{array}{c}\text { Width } \\
(\mathrm{mm})\end{array}$ & $\begin{array}{c}\text { Deformation } \\
\text { value }\end{array}$ \\
\hline $15^{\text {th }} \mathrm{PPL}$ & 30 & 9 & $3.5 E-3$ \\
$15^{\text {th }} \mathrm{BPU}$ & 21 & 7 & $2.9 E-3$ \\
$16^{\text {th }} \mathrm{PPL}$ & 37 & 10 & $4.3 E-3$ \\
$16^{\text {th }} \mathrm{BPU}$ & 41 & 12 & $4.7 E-3$ \\
$17^{\text {th }} \mathrm{PPL}$ & 54 & 13 & $5.8 E-3$ \\
$17^{\text {th }} \mathrm{BPU}$ & 73 & 15 & $6.8 E-3$ \\
\hline
\end{tabular}

certain extent, the final failure of rock will occur along the localization band.

4.2. Evolution Analysis on Displacements around Localization Bands. The deformation field evolution in the process of constant amplitude cyclic loading has been analyzed in detail, in which we can see that the nonuniform deformation of rock increases gradually with the number of cycles, and the localization phenomenon is more and more obvious. In the end, the failure occurs along the deformation localization band. To make further research on the relationship between the deformation evolution of rock and stress condition in the cyclic loading process, the laws of displacement evolution around localization band are analyzed as follows.

4.2.1. Analytical Method of Displacement Evolution. The position of localization band was determined according to the final failure mode (Figure 5) of the specimen and the deformation field (Figure 10) before failure. In order to facilitate analysis, the long nonlinear deformation localization band was divided into two linear localization bands, i.e., the localization band A and the localization band B in Figure 10. 


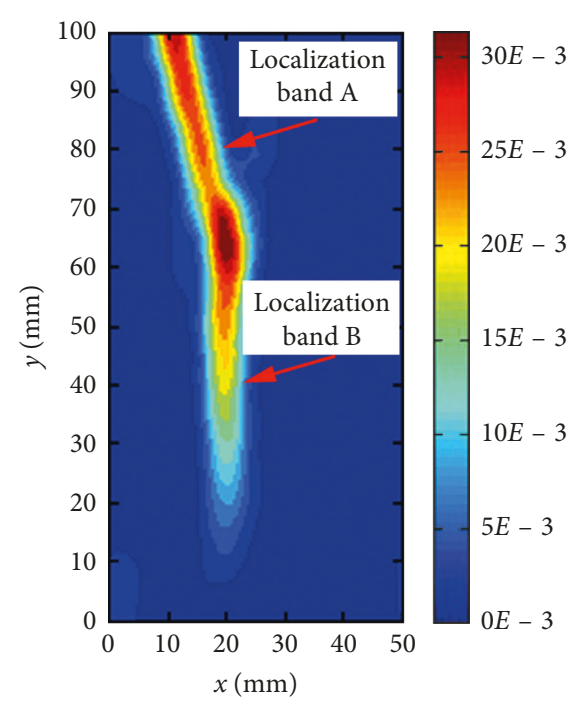

Figure 10: Nephogram of deformation field before failure.

The analytical method of displacement evolution around deformation localization band [43] is shown in Figure 11.

The displacement field of each deformation image which was processed by the digital image correlation method was taken in the first step. Then, determine the displacement calculation region. Five groups of pixels (the corresponding region with the point $p_{1}$ and the point $p_{2}$ as the center points in Figure 11) were selected symmetrically on both sides of localization band, and the distance from the chosen pixels to the identification line of deformation localization band is $a$, whose value is $3 \mathrm{~mm}$. After that, the horizontal displacement $u$ and vertical displacement $v$ were decomposed, respectively, along the orientation parallel and vertical to the deformation localization band. Finally, the differences of the corresponding displacement components between symmetric points were solved as the dislocation displacement (the relative displacement of both sides of the localization band along the direction parallel to the localization band) and tension displacement (the relative displacement of both sides of the localization band along the direction vertical to the localization band) around the deformation localization band, in which the dislocation displacement in a clockwise direction along the deformation localization band and the tension displacement vertical to the localization band were considered positive.

4.2.2. Analysis of Displacement Evolution around Localization Bands. The displacement field of the specimen in the cyclic process was processed through the above analytical method, and the displacement evolution curves of localization band $\mathrm{A}$ and localization band $\mathrm{B}$ were obtained, as shown in Figure 12.

As shown in Figures 12(a)-12(d), the curves of displacements around localization band $\mathrm{A}$ and localization band B fluctuate with cyclic loading stress condition during constant amplitude cyclic loading. Basically, at the loading stage, the displacements produce dislocation along the

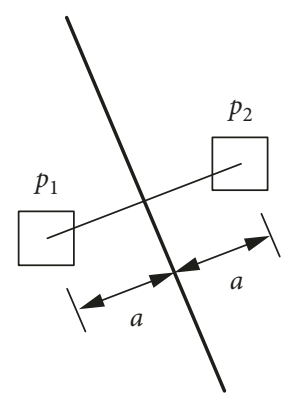

Identification line of

deformation localization band

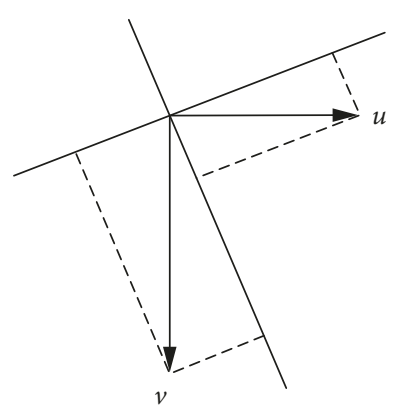

Figure 11: Analytical method of displacement evolution around deformation localization band.

clockwise direction of deformation localization bands and tension vertical to the localization bands; at the unloading stage, the displacements cause dislocation along the counterclockwise direction of deformation localization bands and extrusion vertical to the localization bands. But comparison of the displacement evolution curves with the stress condition finds that the dislocation displacements and the tension displacements around localization bands in each cycle have hysteresis with stress change, no matter at the loading stage or at unloading stage, and continue to evolve towards the original directions when passing the peak point of loading stress or the bottom point of unloading stress. The reasons for hysteresis are the same as the ones for the hysteresis of nonuniform deformation, so no repetition of the explanation occurs here.

To explore the displacement evolution laws around deformation localization bands in relation to the increase of the number of cycles in the constant amplitude cyclic process, the dislocation displacements and the tension displacements at the peak point of loading stress and the bottom point of unloading stress were chosen to draw the displacement evolution curves with the number of cycles, as shown in Figure 13.

Figure 13 indicates that, in the process of constant amplitude cyclic loading, the dislocation displacements and tension displacements around localization A and localization $\mathrm{B}$ at the peak point of loading stress and the bottom point of unloading stress increase with the increase of the number of cycles in general, indicating displacements are evolving step by step. It suggests that, before the $10^{\text {th }}$ cycle, the value of displacements increases slowly. After the $10^{\text {th }}$ loading cycle, the value of displacements increases dramatically compared with the earlier loading cycle, and the slope of displacement curves overall increases with the number of cycles increasing. The displacements have the same evolution laws as that for the nonuniform deformation of rock. And in the cyclic loading process, two stages about displacement evolution exist: slow and fast evolution stage.

So far, in the process of uniaxial constant amplitude cyclic loading of rock, it is rarely seen to choose a scientific index that can reflect the main characteristics of nonuniform deformation field of rock specimens to analyze the evolution of nonuniform deformation and explore the 


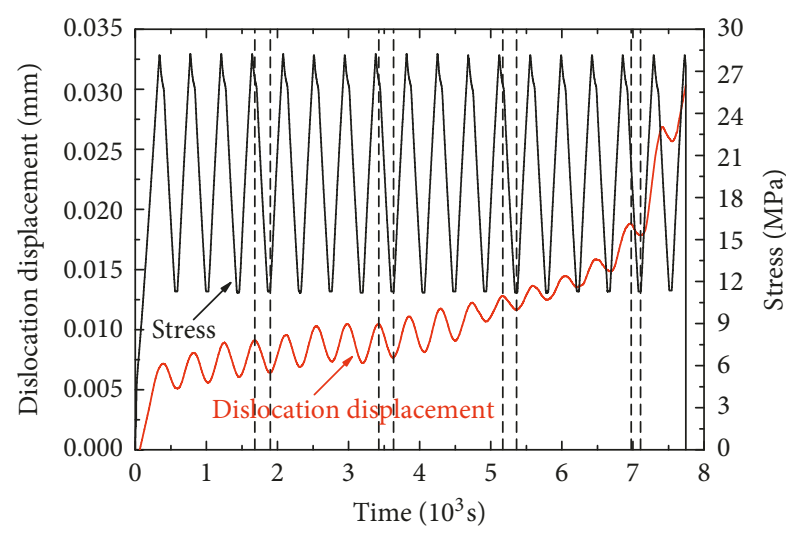

(a)

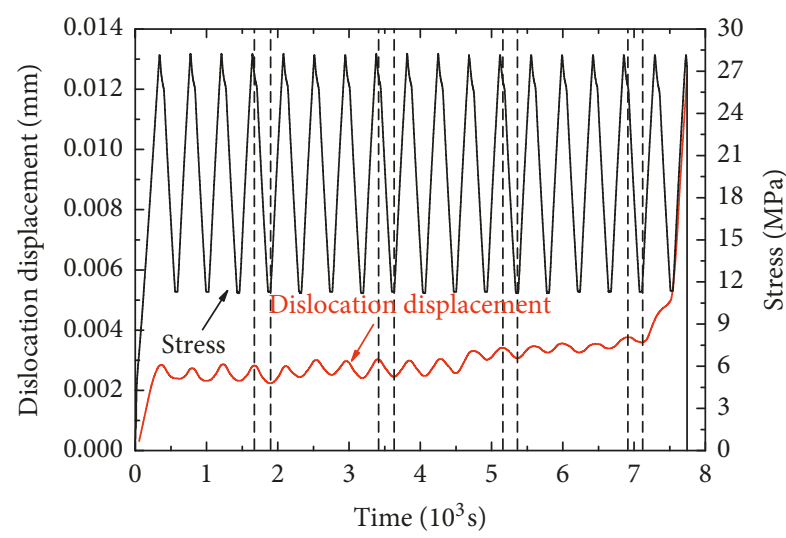

(c)

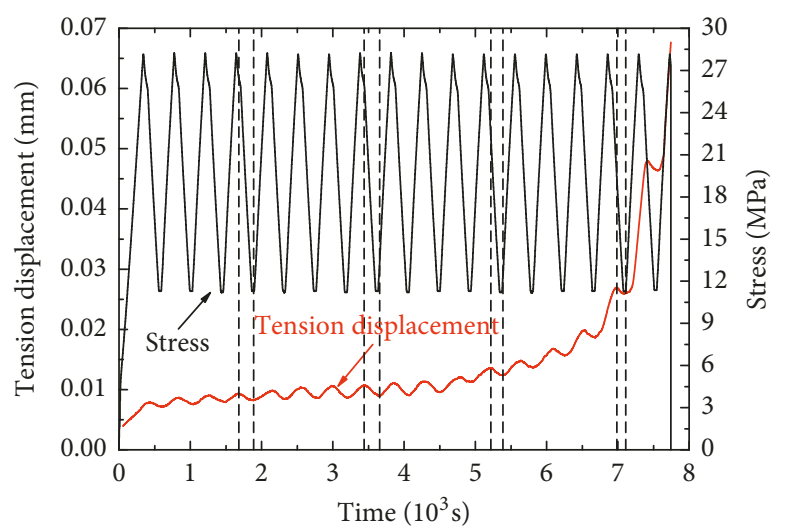

(b)

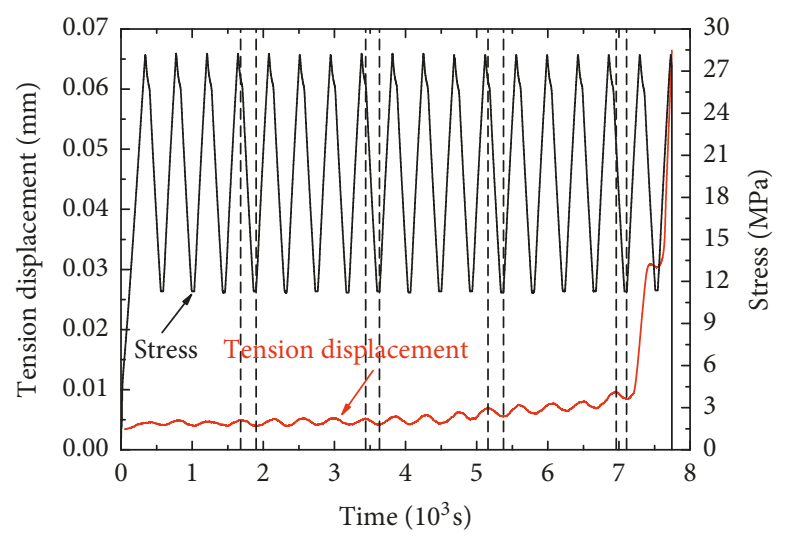

(d)

Figure 12: Displacement evolution curves around localization bands: (a) dislocation displacement of localization band A; (b) tension displacement of localization band A; (c) dislocation displacement of localization band B; (d) tension displacement of localization band B.

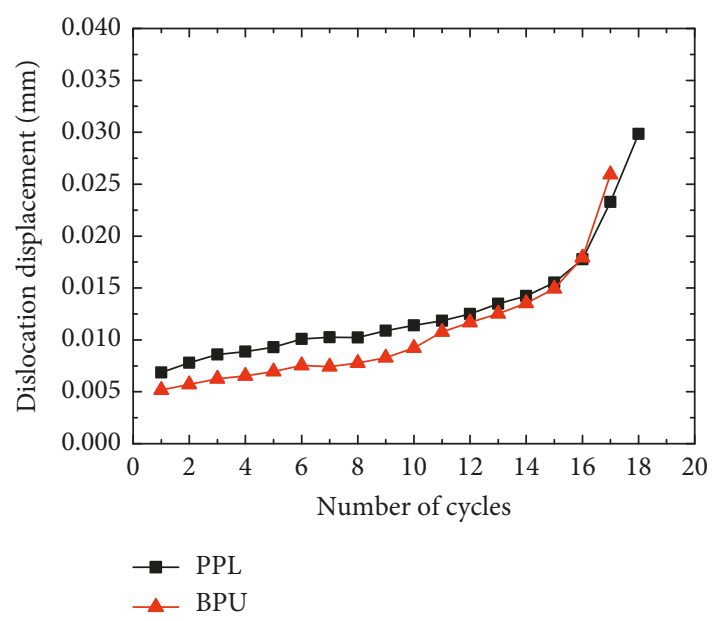

(a)

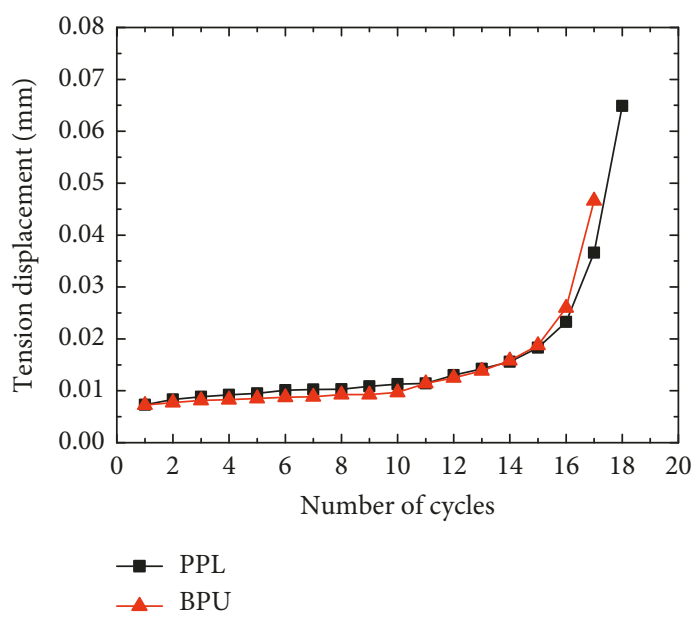

(b)

Figure 13: Continued. 


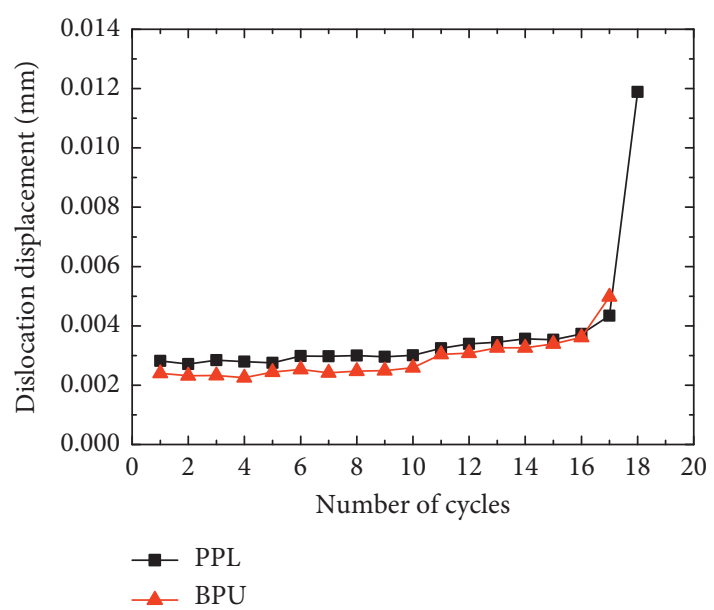

(c)

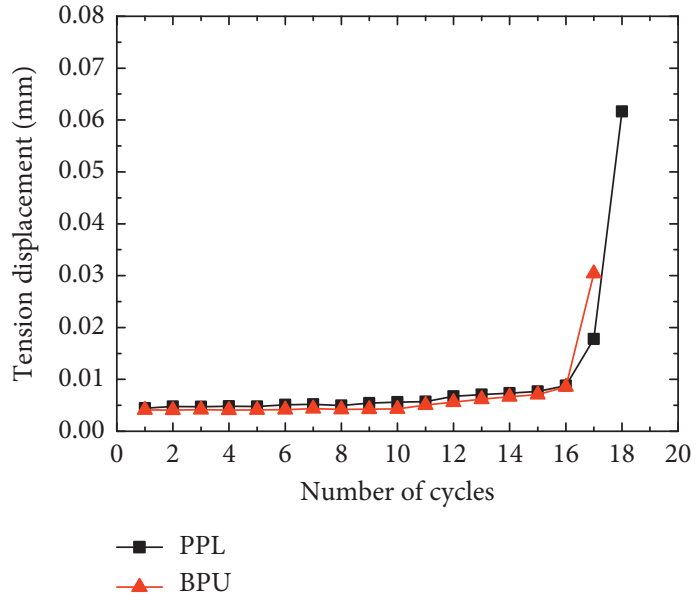

(d)

Figure 13: Displacement evolution curves at the peak point of loading stress and the bottom point of unloading stress: (a) dislocation displacement of localization band A; (b) tension displacement of localization band A; (c) dislocation displacement of localization band B; (d) tension displacement of localization band B.

displacement evolution of deformation localization bands based on DICM. The research results are of positive significance for understanding the deformation and failure of rocks during the cyclic process, but there are some insufficiencies. In the latter study, it is necessary to carry out a large number of tests for different types of rocks under different loading methods and different loading rates, as well as combining the method of CT scanning and scanning electron microscopy, to explore the relationships between the nonuniform deformation of rock and the microstructure within the rock, as well as the relationships between the nonuniform deformation of rock and the failure mode of rock.

\section{Conclusions}

Uniaxial constant amplitude cyclic loading tests of sandstones were carried out, and the deformation images of specimen surfaces during the tests were captured by CCD cameras. Based on the digital image correlation method, the nonuniform deformation and displacement evolution were analyzed, and the following conclusions can be drawn.

By introducing the statistical index, the nonuniform deformation degree was quantified, the nonuniform deformation of rock gradually increases with the cyclic loading number increasing and fluctuates with the loading stress condition on the whole; compared with the time of stress change, nonuniform deformation experiences hysteresis, no matter at the loading stage or at unloading stage. In general, the nonuniform deformation has two evolution stages with the number of cycles, i.e., slow and fast nonuniform deformation evolution stage.

At the loading stage or unloading stage of the entire cyclic process, the nonuniform deformation of rock increases with the number of cycles increasing under the same stress condition. In each loading cycle, the nonuniform deformation at the unloading stage is bigger than that at the loading stage under the same stress condition. This is caused by the effect of cyclic loading, and cyclic loading can cause damage accumulation in rock materials.

As to the displacement evolution laws around localization bands, the curves of displacements fluctuate with loading stress condition during the cyclic process. Basically, in the loading and unloading stages, the displacements produce dislocation along the opposite direction parallel to the deformation localization bands and cause tension or extrusion along the opposite direction vertical to the deformation localization bands. The dislocation displacements and the tension displacements lag behind the loading and unloading stress, having the same hysteresis laws as nonuniform deformation. Overall, the values of the dislocation displacements and the tension displacements around localization bands increase with the increase of the number of cycles, and there exist slow displacement evolution stage and fast displacement evolution stage, just as the evolution stages of nonuniform deformation.

\section{Data Availability}

The raw data will be provided upon request to the corresponding author.

\section{Conflicts of Interest}

The authors declare that they have no conflicts of interest.

\section{Acknowledgments}

The authors are grateful to the National Natural Science Foundation of China (Grant nos. 50904071 and 51274207) for the financial support to this work.

\section{References}

[1] L. S. Costin and D. J. Holcomb, "Time-dependent failure of rock under cyclic loading," Tectonophysics, vol. 79, no. 3-4, pp. 279-296, 1981. 
[2] S. K. Singh, "Fatigue and strain hardening behaviour of graywacke from the flagstaff formation, New South Wales," Engineering Geology, vol. 26, no. 2, pp. 171-179, 1989.

[3] S. K. Ray, M. Sarkar, and T. N. Singh, "Effect of cyclic loading and strain rate on the mechanical behaviour of sandstone," International Journal of Rock Mechanics and Mining Sciences, vol. 36, no. 4, pp. 543-549, 1999.

[4] J. Xu, X. F. Xiang, H. Wang, W. Z. Wang, and X. G. Yang, "Experimental study on rock deformation characteristics under cycling loading and unloading conditions," Chinese Journal of Rock Mechanics and Engineering, vol. 25, no. 1, pp. 3040-3045, 2006.

[5] M. M. He, Y. S. Chen, N. Li, and C. H. Zhu, "Deformation and energy characteristics of sandstone subjected to uniaxial cyclic loading," Journal of China Coal Society, vol. 40, no. 8, pp. 1805-1812, 2015.

[6] R. G. Vaneghi, B. Ferdosi, A. D. Okoth, and B. Kuek, "Strength degradation of sandstone and granodiorite under uniaxial cyclic loading," Journal of Rock Mechanics and Geotechnical Engineering, vol. 10, no. 1, pp. 117-126, 2018.

[7] M. N. Bagde and V. Petroš, "Fatigue and dynamic energy behaviour of rock subjected to cyclical loading," International Journal of Rock Mechanics and Mining Sciences, vol. 46, no. 1, pp. 200-209, 2009.

[8] M. K. Jafari, F. Pellet, M. Boulon, and K. A. Hosseini, "Experimental study of mechanical behaviour of rock joints under cyclic loading," Rock Mechanics and Rock Engineering, vol. 37, no. 1, pp. 3-23, 2004.

[9] J. A. White, "Anisotropic damage of rock joints during cyclic loading: constitutive framework and numerical integration," International Journal for Numerical and Analytical Methods in Geomechanics, vol. 38, no. 10, pp. 1036-1057, 2014.

[10] Y. L. Chen, Z. A. Wei, and Q. G. Zhang, "Experimental study on Felicity effect of acoustic emission in rock under cyclic loading and tiered cyclic loading," Journal of China Coal Society, vol. 37, no. 2, pp. 226-230, 2012.

[11] D. Xia, T. H. Yang, P. T. Wang, and Y. C. Zhao, "Experimental study of acoustic emission characteristics of dry and saturated rocks during cyclic loading process," Journal of China Coal Society, vol. 39, no. 7, pp. 1243-1247, 2014.

[12] H. R. Li, C. H. Yang, Y. G. Liu, and B. W. Wang, "Experimental study of ultrasonic velocity and acoustic emission properties of salt rock under uniaxial compression load," Chinese Journal of Rock Mechanics and Engineering, vol. 33, no. 10, pp. 2107-2116, 2014.

[13] B. Fu, Z. H. Zhou, H. Q. Wang, and Y. X. Wang, "Precursor information study on acoustic emission characteristics of marble under uniaxial cyclic loading-unloading," Journal of China Coal Society, vol. 41, no. 8, pp. 1946-1953, 2016.

[14] J. Song, S. C. Li, B. Liu et al., "Study on resistivity response law of limestone in processes of constant amplitude and tiered cyclic loading and unloading," Chinese Journal of Rock Mechanics and Engineering, vol. 34, no. 2, pp. 3880-3887, 2015.

[15] H. Song, H. Zhang, Y. Kang, G. Huang, D. Fu, and C. Qu, "Damage evolution study of sandstone by cyclic uniaxial test and digital image correlation," Tectonophysics, vol. 608, no. 6 , pp. 1343-1348, 2013.

[16] H. Song, H. Zhang, D. Fu, and Q. Zhang, "Experimental analysis and characterization of damage evolution in rock under cyclic loading," International Journal of Rock Mechanics and Mining Sciences, vol. 88, pp. 157-164, 2016.

[17] J. W. Zhou, X. G. Yang, W. X. Fu et al., "Experimental test and fracture damage mechanical characteristics of brittle rock under uniaxial cyclic loading conditions," Chinese Journal of
Rock Mechanics and Engineering, vol. 29, no. 6, pp. 1172-1183, 2010.

[18] J. Zhou, X. Yang, Z. Yang, H. Li, and H. Zhou, "Micromechanics damage modeling of brittle rock failure processes under compression," International Journal of Computational Methods, vol. 10, no. 6, p. 1350034, 2013.

[19] Y. F. Dong, L. G. Wang, X. F. Liu, and L. Q. Dai, “The experimental research of the infrared radiation in the process of rock deformation," Rock and Soil Mechanics, vol. 22, no. 2, pp. 134-137, 2001.

[20] K. Mogi, "Source locations of elastic shocks in the fracturing processes in rocks," Bulletin of the Earthquake Research Institute Tokyo Imperial University, vol. 46, pp. 1103-1125, 1968.

[21] C. H. Scholz, "Experimental study of the fracturing process in brittle rock," Journal of Geophysical Research, vol. 73, no. 4, pp. 1447-1454, 1968.

[22] Y. M. Song, S. P. Ma, X. B. Yang, and X. Wang, "Experimental investigation on failure of rock by digital speckle correlation methods," Chinese Journal of Rock Mechanics and Engineering, vol. 30, no. 1, pp. 170-175, 2011.

[23] L. Wu, S. Liu, Y. Wu, and H. Wu, "Changes in infrared radiation with rock deformation," International Journal of Rock Mechanics and Mining Sciences, vol. 39, no. 6, pp. 825-831, 2002.

[24] H. W. Ji, Y. W. Qin, and J. L. Chen, "Thermal stress measurement of quartz oscillator module packaging," Acta Mechanica Solida Sinica, vol. 14, no. 3, pp. 251-258, 2001.

[25] I. Yamaguchi, "A laser-speckle strain gauge," Journal of Physics E: Scientific Instruments, vol. 14, no. 11, pp. 1270-1273, 1981.

[26] W. H. Peters and W. F. Ranson, "Digital imaging techniques in experimental stress analysis," Optical Engineering, vol. 21, no. 3, pp. 427-431, 1982.

[27] Z. H. Jiang, B. H. Fei, D. S. Zhang, and S. P. Ma, "Application and prospect of digital speckle correlation method on wood science," Engineering Science, vol. 5, no. 11, pp. 1-7, 2003.

[28] S. P. Ma and G. C. Jin, "Digital speckle correlation method improved by genetic algorithm," Acta Mechanica Solida Sinica, vol. 16, no. 4, pp. 366-373, 2003.

[29] J. B. Rui, G. C. Jin, and B. Y. Xu, "A new digital speckle correlation method and its application," Acta Mechanica Sinica, vol. 26, no. 5, pp. 599-607, 1994.

[30] Y. Q. Tan, L. Zhang, M. Guo, and L. Y. Shan, "Investigation of the deformation properties of asphalt mixtures with DIC technique," Construction and Building Materials, vol. 37, no. 1, pp. 581-590, 2012.

[31] P. Zhou and K. E. Goodson, "Subpixel displacement and deformation gradient measurement using digital image/ speckle correlation (DISC)," Optical Engineering, vol. 40, no. 8, pp. 1613-1620, 2001.

[32] J. D. Chen, S. P. Ma, S. J. Liu, and G. C. Jin, “An experimental study of the failure process of en-echelon fault structure using the digital speckle correlation method," Chinese Journal of Geophysics, vol. 48, no. 6, pp. 1350-1356, 2005.

[33] Z.-F. Zhang, Y.-L. Kang, H.-W. Wang, Q.-H. Qin, Y. Qiu, and X.-Q. Li, “A novel coarse-fine search scheme for digital image correlation method," Measurement, vol. 39, no. 8, pp. 710718, 2006.

[34] C. Liu, Y. T. Dai, M. L. Dai et al., "Deformation measurement by two-dimensional multi-camera full-field digital image correlation," Acta Optica Sinica, vol. 36, no. 12, pp. 97-105, 2016. 
[35] H. W. Wang, Y. L. Kang, and H. P. Xie, "Advance in digital speckle correlation method and its application," Advances in Mechanics, vol. 35, no. 2, pp. 195-203, 2005.

[36] C. Xiao, Investigation of Digital Image Correlation Method in Damage and Fracture Experiment, Tianjin University, Tianjin, China, 2013.

[37] Y. R. Zhao, Y. M. Xing, J. Y. Huang, and A. F. Jiang, "Study on the fiber-reinforced concrete pull-out test using digital image correlation method," Engineering Mechanics, vol. 27, no. 6, pp. $169-175,2010$.

[38] Y. M. Song, T. Z. Xing, T. B. Zhao, Z. X. Zhao, and P. B. Gao, "Acoustic emission characteristics of deformation field development of rock under uniaxial loading," Chinese Journal of Rock Mechanics and Engineering, vol. 36, no. 3, pp. 534-542, 2017.

[39] X. B. Yang, Y. M. Song, and T. B. Zhao, Mechanics Analysis of Deformation and Failure of Rock, China Coal Industry Publishing House, Beijing, China, 2016.

[40] X. B. Yang, X. X. Han, E. L. Liu, Z. P. Zhang, T. J. Wang, and L. H. Zhang, "Properties of non-uniform deformation evolution of rock under uniaxial cyclic loading and unloading," Journal of China Coal Society, vol. 43, no. 2, pp. 449-456, 2018.

[41] J. W. Zhou, W. Y. Xu, and X. G. Yang, "A microcrack damage model for brittle rocks under uniaxial compression," $M e$ chanics Research Communications, vol. 37, no. 4, pp. 399-405, 2010

[42] Y. M. Song, Digital Speckle Correlation Method for NonHomogenous Deformation Field Measurement and Its Application to the Experimental Study of Rock Failure, Tsinghua University, Beijing, China, 2010.

[43] Y. M. Song, Y. D. Jiang, S. P. Ma, X. B. Yang, and T. B. Zhao, "Evolution of deformation fields and energy in whole process of rock failure," Rock and Soil Mechanics, vol. 33, no. 5, pp. 1352-1365, 2012. 


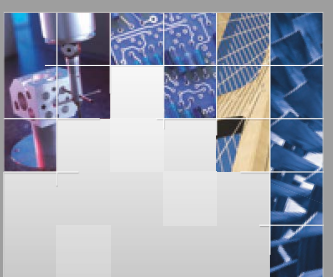

\section{Enfincering}
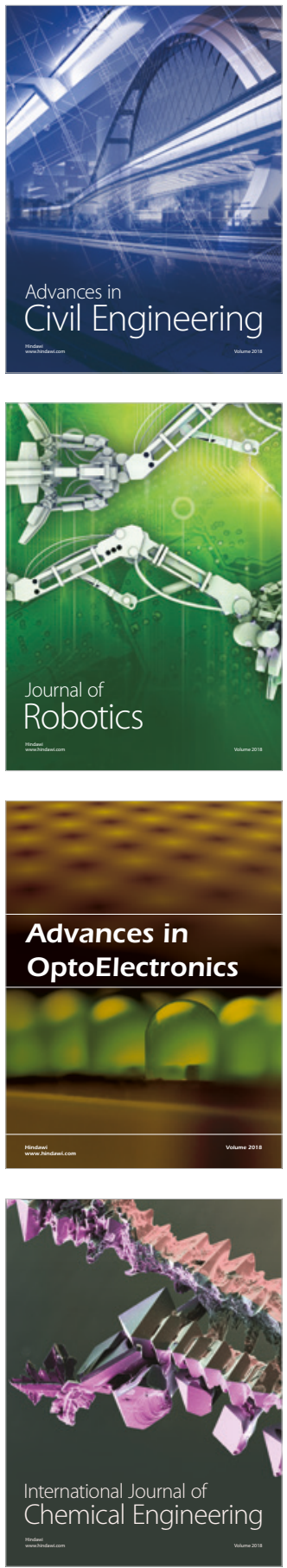

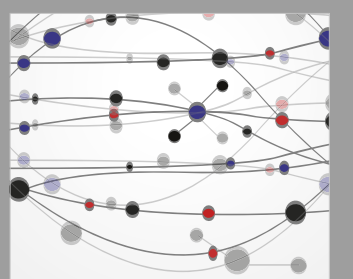

\section{Rotating \\ Machinery}

The Scientific World Journal

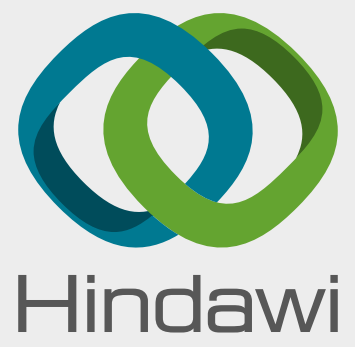

Submit your manuscripts at

www.hindawi.com
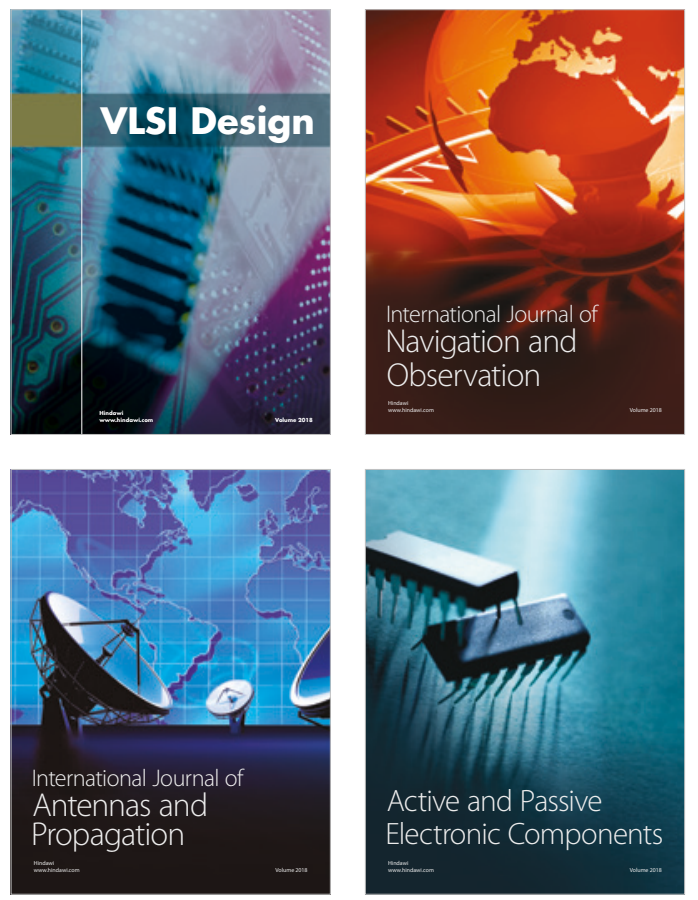
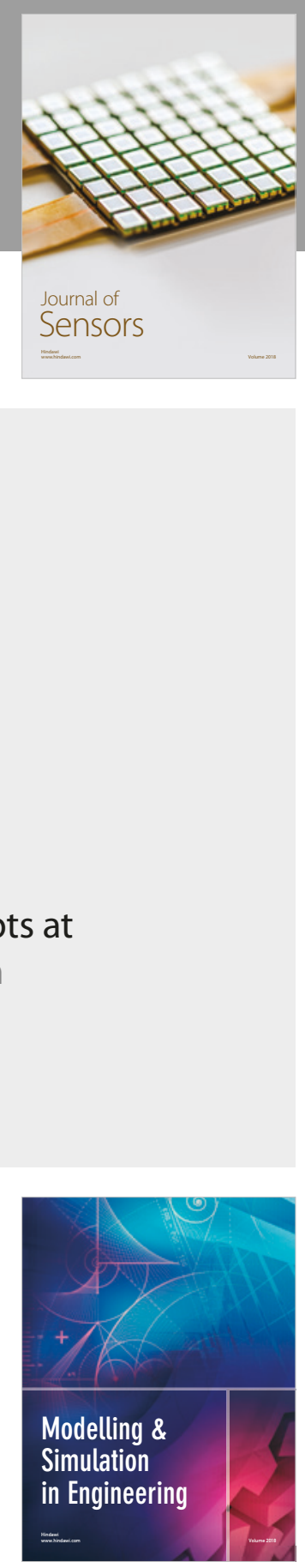

\section{Advances \\ Multimedia}
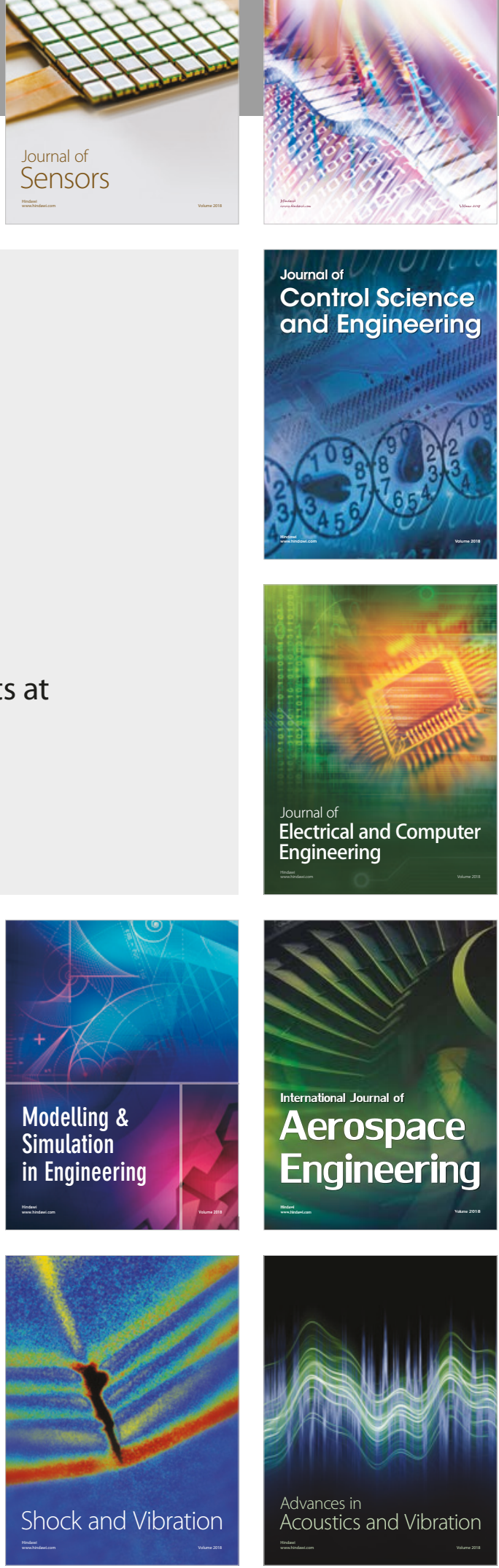